\title{
O uso autogerenciado de videoaulas de química na preparação dos estudantes para exames de ingresso no ensino superior
}

Charles Silveira Nunes - Instituto de Química/UFRGS - e-mail: charlesnun@yahoo.com.br Marcelo Leandro Eichler - Instituto de Química/UFRGS - e-mail: exlerbr@gmail.com

\begin{abstract}
Resumo
A ampliação da distribuição de recursos didáticos tem mudado as práticas de ensino e de aprendizagem de alunos e de professores. Este artigo relata uma pesquisa sobre a apropriação de recursos didáticos de tipo videoaulas de química por estudantes em preparação para exames de admissão no ensino superior. Como método foi utilizada uma pesquisa de levantamento, através de questionário estruturado, com a participação de 114 estudantes recém ingressos no ensino superior. Destes, $98(85,96 \%)$ afirmaram terem usado videoaulas de Química com alguma frequência, contra $16(14,04 \%)$ que nunca usaram. Para os alunos que utilizaram videoaulas de Química, 25,53\% afirmaram que essa ferramenta foi o método principal, frente a $74,47 \%$ que declararam ter sido um método complementar. De forma geral, foi possível constatar que o uso de videoaulas de Química de maneira autogerenciada foi um recurso recorrente e apropriado para os estudantes durante sua preparação para o ingresso no ensino superior.
\end{abstract}

Palavras-Chaves: videoaulas; internet; autogerenciada; ensino superior.

\section{The self-managed use of video chemistry lessons in the training of students for admission exams in higher education}

\begin{abstract}
The expansion of the distribution of didactic resources has changed the teaching and learning practices of students and teachers. This article reports a research on the use of chemistry videos by students in preparation for admission exams in higher education. Thus, a quantitative investigation was carried out using the survey method of "Survey", through the application of a questionnaire to 114 students. Of these, $98(85.96 \%)$ reported having used Chemistry videotapes with some frequency, against 16 (14.04\%) that they never used. For the students who used Chemistry videotapes, $25.53 \%$ stated that this tool was the main method, compared to $74.47 \%$ that they declared to be a complementary method. In general, it was possible to verify that the use of chemistry videotapes in a self-managed way was a recurrent and appropriate resource for the students during their preparation for entry into higher education.
\end{abstract}

Keywords: video classes; internet; self-managed; higher education.

\section{INTRODUÇÃO}

As novas tecnologias, especialmente as conectadas à internet, como computadores, notebooks, smartphones, tablets e afins, cada vez mais tem interferido nas nossas construções de relações, seja entre os indivíduos ou entre estes com o meio. Nessa perspectiva, o campo da educação também vem sofrendo tal interferência, principalmente com o uso de tecnologias as quais podem possibilitar um processo de ensino e de aprendizagem mais dinâmico, interativo e contextualizado com a realidade dos alunos. Entre as inúmeras ferramentas tecnológicas disponíveis para utilização no contexto educacional, este trabalho se direcionará exclusivamente para os recursos audiovisuais, em particular, as videoaulas. 
O uso de videoaulas está atualmente compreendido na idéia de aprendizagem móvel (Mobile Learning ou m-learning). A experiência da tão somente visualização de uma aula online pode ser expandida, uma vez que, segundo Melo e Boll (2014), inserido no contexto da aprendizagem móvel e a partir da utilização de dispositivos específicos, há a possibilidade de integração das mídias, o compartilhamento das ideias e de experiências culturais. Contreras, Ellensohn e Barin (2017) afirmam que a mobilidade foi possível diante a popularização e difusão de dispositivos capazes de acessar plataformas e reproduzir formatos de vídeos em qualquer lugar e hora.

Constata-se que essa é uma ferramenta que auxilia na aprendizagem, uma vez que, possuem a capacidade de serem atrativas e despertarem a atenção do público, gerando muita aceitação entre os jovens em idade escolar (CANDEIAS e CARVALHO, 2016); têm a habilidade de alcançar, sensibilizar e persuadir a quem o assiste, pois se trata uma junção de áudio e vídeo (FORTUNA et. al., 2017); e, compreendem um meio de desenvolvimento de novas habilidades cognitivas, quer dizer, novos modos de aprender, mais autônomos e colaborativos (SOUZA FILHO, SOUZA e GIBIN, 2017).

Esta é outra característica importante da videoaula que foi destacada neste trabalho: a exigência por um lado, e promoção por outro, de uma capacidade de autogerenciamento por parte do estudante - principalmente direcionando sua utilização em um ambiente educacional fora da sala de aula.

Voltando-se exclusivamente a análise do universo de caracterização da ciência da química, sabe-se que esta apresenta forte relação com o campo experimental e, de maneira geral, possui conteúdos abstratos e de difícil compreensão e visualização por parte dos alunos (LOCATELLI, ZOCH e TRENTIN, 2015). É válido mencionar que a disciplina de química, em relação à estrutura curricular em nível da educação básica, está mais presente na vida dos estudantes no período do ensino médio - estágio de fundamental importância para o indivíduo, seja enquanto aluno ou cidadão, onde deve haver a melhor compreensão de conceitos científicos e sua relação com o cotidiano. No entanto, após a conclusão dessa etapa, de forma imediata ou posterior, grande parte dos alunos decide dar continuidade em sua vida estudantil, incluindo a acesso ao ensino superior (CASTRO, 2013). Considera-se, todavia, que para tal é necessário uma preparação adequada, uma vez que, grande parte das instituições de ensino superior se utiliza da realização de processos seletivos específicos. Há de se considerar também que estes são contemplados em sua grande maioria por provas que podem ter, por exemplo, um elevado grau de complexidade das questões ou uma alta densidade de candidatos por vaga. De forma sucinta, estas provas podem ser a nível nacional, como o Exame Nacional do Ensino Médio (ENEM), ou realizadas pela própria instituição, os conhecidos vestibulares.

Assim, dentro desse cenário, no qual as Tecnologias de Informação e Comunicação (TICs), sobretudo as videoaulas, oportunizam um ambiente de maior possibilidade de estudos para os alunos, surge a questão norteadora deste estudo: quais os motivos (ou não) para o uso de videoaulas de Química durante a preparação autônoma para o ingresso no ensino superior? Como forma de buscar a resposta o objetivo deste trabalho centrou-se em analisar o uso de videoaulas de Química, de forma autogerenciada, na preparação dos ingressantes em cursos com peso 3 em Química no vestibular da UFRGS.

\section{ABORDAGEM METODOLÓGICA}

No presente estudo a abordagem utilizada foi de caráter quantitativo e realizada através do método de pesquisa de "Levantamento" (Survey), na qual oferece uma descrição quantitativa ou numérica de tendências, atitudes ou opiniões de uma 
população ao estudar uma amostra dela (CRESWELL, 2007). Assim, utilizou-se de um questionário construído de forma estruturada para realizar o levantamento, ou seja, generalizações de uma população específica.

Os sujeitos foram os alunos ingressantes na Universidade Federal do Rio Grande do Sul (UFRGS) oriundos do vestibular 2018, e anteriores recentes, cujos cursos apresentam peso 3 em química (Engenharia de Materiais, Farmácia, Nutrição e Química - Bacharelado, Industrial e Licenciatura).

O questionário compreendeu ao total 84 itens, distribuídos em 5 seções, a saber: A ("Pessoal") - 2 itens; B ("Durante a minha preparação para o ingresso no ensino superior") - 72 itens; C ("Ensino Médio") - 2 itens; D (“ENEM”) - 3 itens; e, E ("UFRGS") - 5 itens.

Em especial na seção B, grande parte dos itens utilizou escala de concordância de 5 pontos. Os itens de algumas questões foram criados a fim compreender aspectos essenciais que tangem aos processos de ensino e de aprendizagem tendo por base o recurso videoaula: (i) didático, em relação aos próprios vídeos ou outros materiais fornecidos; (ii) autogerenciamento; (iii) interação virtual social; (iv) avanços tecnológicos; e, (v) financeiro. Faz-se necessário salientar que tais aspectos não aparecem explicitados para os respondentes, tratando-se de uma forma de melhor organização dos itens tanto para a estruturação da questão quanto da analise e discussão dos resultados.

Ainda sobre a Seção B, a partir da estrutura dos itens que a contém, é possível constatar dois grupos de respondentes em relação ao uso de videoaulas de Química. Os possíveis percursos destes respondentes ficam evidenciados na Figura 1.

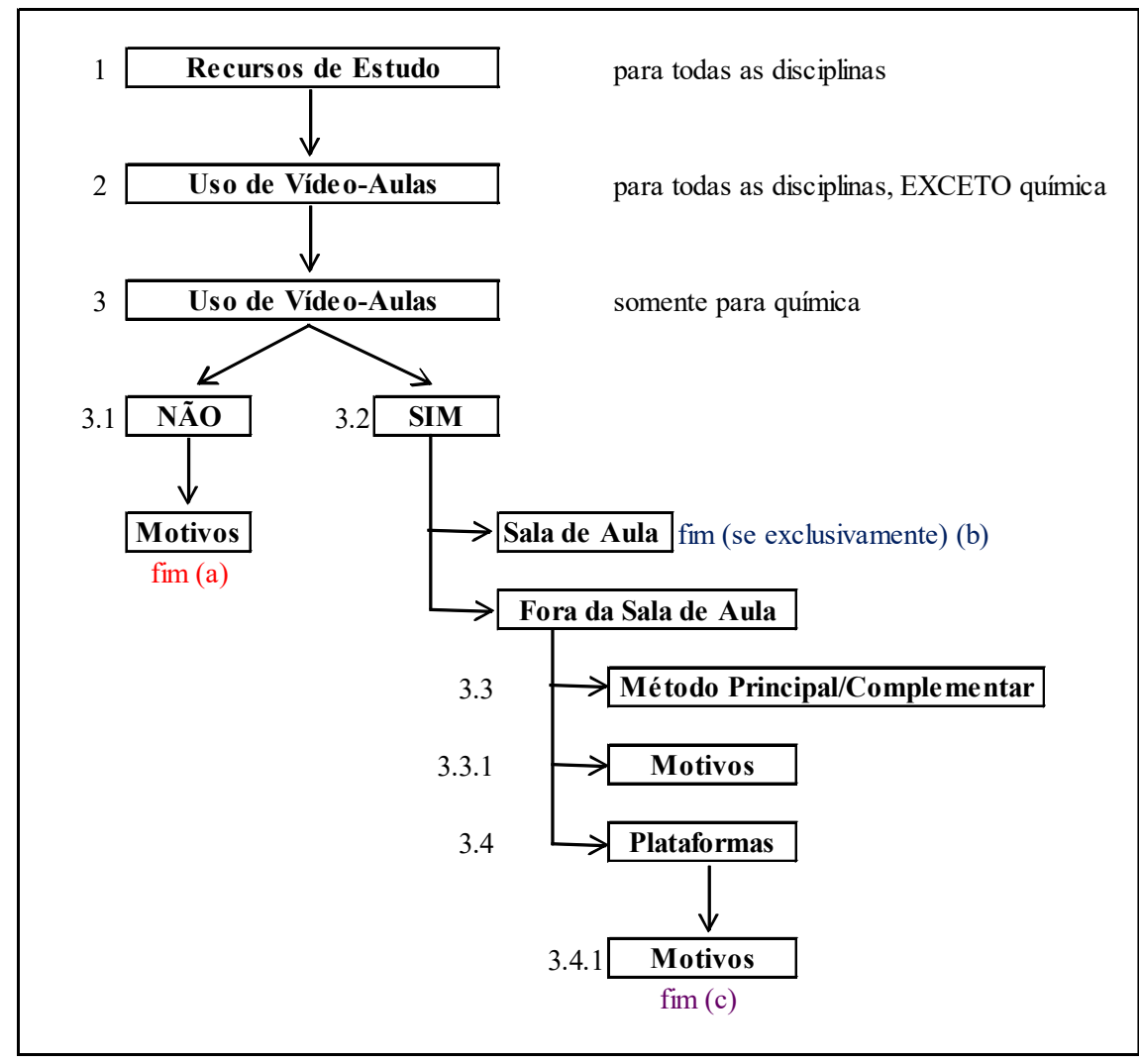

Figura 1 - Possíveis percursos na Seção B 
Tal questionário foi previamente validado por um grupo de alunos "calouros" ingressantes em um faixa de período entre 2014 e 2017, sendo todos do curso de Química - por conveniência.

Os questionários foram entregues diretamente em aulas específicas dos respectivos cursos juntamente com a guia de orientação Os questionários foram numerados e tabulados usando planilha do Microsoft Excel 2010. Utilizou-se o mesmo software para a análise das variáveis analisadas.

\section{RESULTADOS E DISCUSSÕES}

Ao todo foram aplicados 139 questionários, em aulas de disciplinas introdutórias de Química. Nessas disciplinas, 25 estudantes pertenciam a cursos que não possuíam peso 3 na disciplina de química no exame vestibular, por isso seus questionários não foram considerados nessa avaliação. Assim, em termos de análise dos dados, se considerou 114 questionários como válidos. A Tabela 1 mostra de forma mais detalhada a caracterização destes.

Tabela 1 - Caracterização dos alunos respondentes

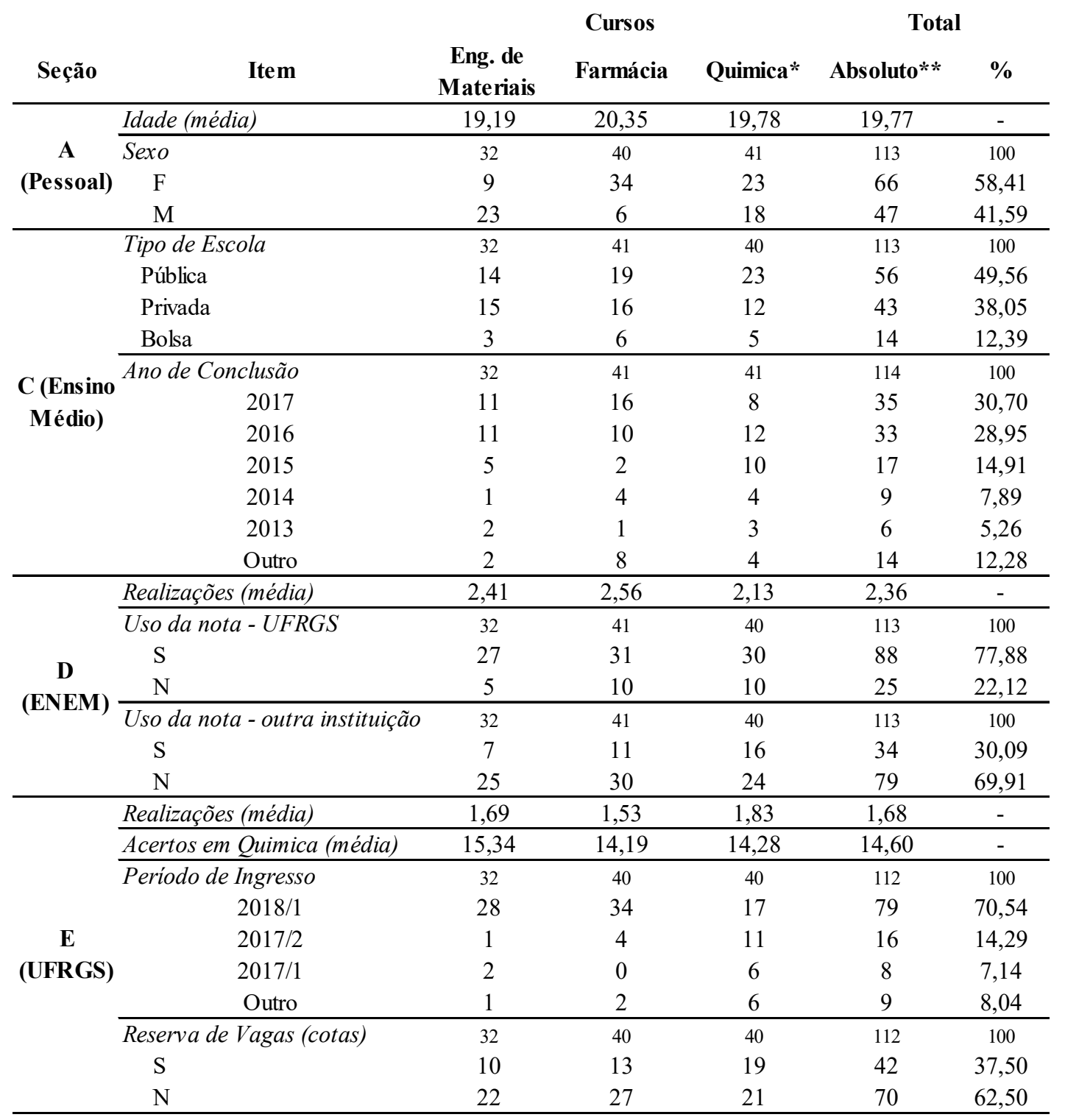

*contempla as ênfases bacharel, industrial e licenciatura.

**em alguns casos o somatório não confere como o apresentado na tabela 2 pois são resultados "em branco". 
Entre algumas semelhanças dos alunos em seus cursos é possível destacar, por exemplo, a idade média (19,77 anos), a quantidade de realizações média do ENEM $(2,36)$ e do vestibular da UFRGS $(1,68)$ e o número médio de acertos em Química no vestibular da UFRGS $(14,60)$. Identificou-se também que a maioria dos alunos concluiu o ensino médio nos anos de 2017 e 2016 (59,65\%) e que utilizaram a nota do ENEM como parte do processo seletivo da UFRGS $(77,88 \%)$.

As questões da seção B serão apresentadas detalhadamente a seguir.

\section{- Utilizei os seguintes métodos/recursos de estudo}

Esta questão vai ao encontro do conceito "Estilo de Aprendizagem" abordado por Martins e Piontkewicz (2013). Os autores definem este como uma característica com a qual o indivíduo prefere aprender, ou seja, através de uma leitura, em uma aula presencial, por meio de simulações, ou ouvindo. A Figura 2 mostra a frequência de uso de alguns métodos ou recursos de estudo utilizados pelos alunos.

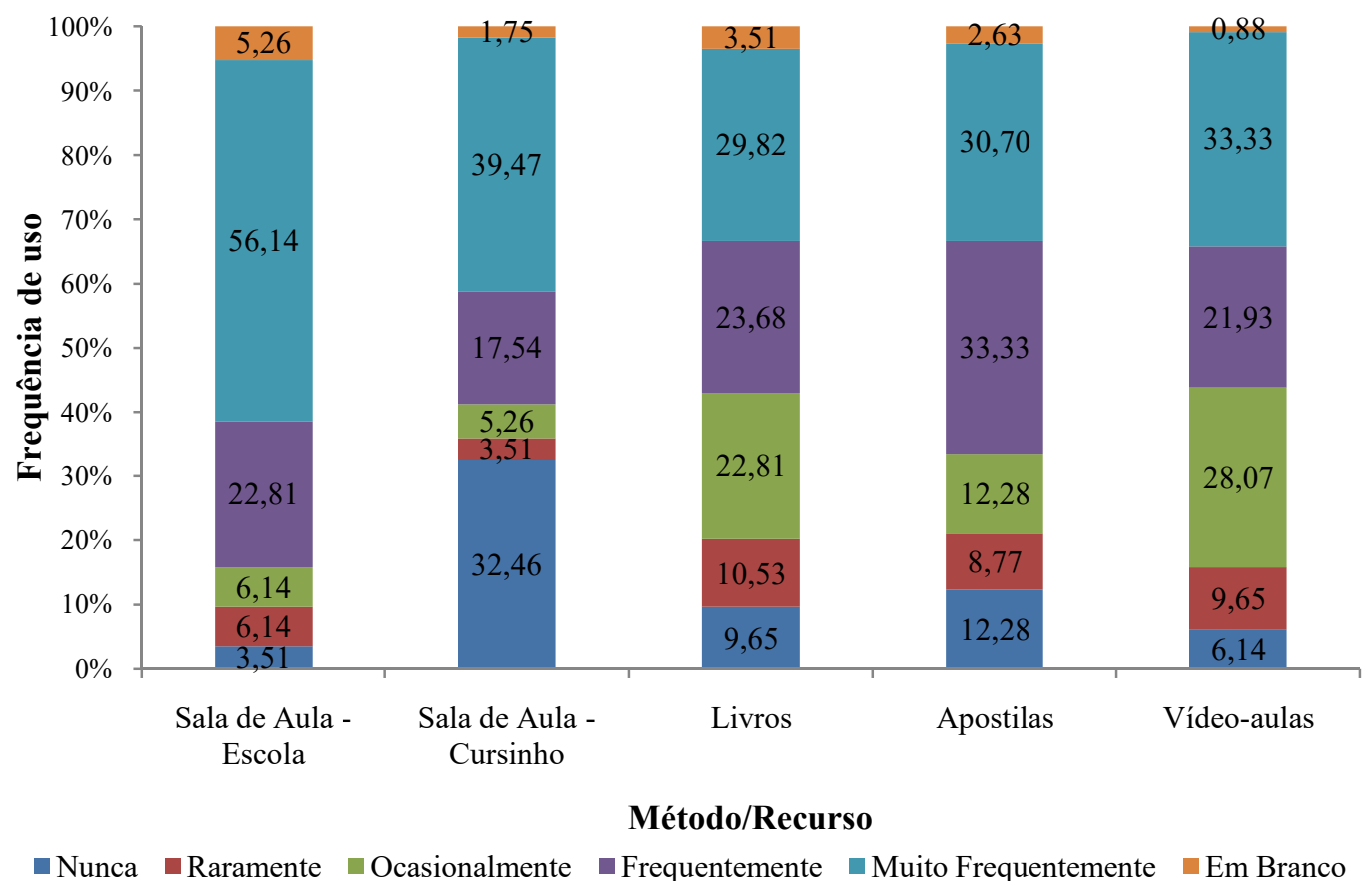

Figura 2 - Métodos/recursos de estudo

Ao analisar o item que obteve maior freqüência "Nunca", o resultado aponta para "Sala de Aula - Cursinho". O valor indicado, 32,46\%, é aproximadamente três vezes superior ao item "Apostila", 12,28\% - que atingiu a segunda maior freqüência "Nunca". Por outro lado, fica evidenciado que quanto à freqüência "Muito Frequentemente", o item "Sala de Aula - Escola" foi o que obteve o maior número de indicações. Talvez tal fato possa ter contribuído para esse item ter obtido a maior média ponderada entre todos, atingindo o valor de 4,29. É interessante ressaltar que os dados supramencionados, em relação a "Sala de Aula - Cursinho" e "Sala de Aula - Escola", contrastam totalmente com os apresentados por Castro (2013). A autora apontou que a maioria dos alunos pesquisados utilizou cursinho vestibular ou ENEM (pago ou alternativo) e que não considerava a sala de aula como método/recurso de estudo principal para os processos seletivos de ingresso no ensino superior. "Eles não percebem o percurso de onze/doze anos de escola como preparação para os exames de vestibular" (CASTRO, 2013). 
A partir do indicativo média ponderada é possível visualizar que o item "Videoaulas" atingiu o segundo maior valor, com 3,67. Também deve ser levado em consideração que apenas 7 alunos dos $114(6,14 \%)$ apontaram "Nunca" terem utilizado esse recurso, ou seja, os outros $95,86 \%$ dos alunos utilizaram videoaulas como estudo para o ENEM ou vestibular com alguma frequência. Medina, Braga e Rego (2015) em uma investigação com alunos do terceiro ano do ensino médio sobre o uso de videoaulas de Ciências da Natureza (Química, Física e Biologia) obtiveram que 52,9\% utilizaram esse recurso "Sempre ou Muitas vezes" para "Revisar os conteúdos do Enem". Obviamente não é possível realizar uma comparação direta entre os dados da pesquisa supramencionada com os deste trabalho. Contudo, é possível encontrar alguns pontos em comum, entre os quais destaca-se a utilização de videoaulas como fonte de estudo para o Enem, por exemplo.

\section{- Utilizei videoaulas das seguintes disciplinas}

A Tabela 2 mostra média ponderada da indicação dos respondentes ao quanto assistiram videoaulas das disciplinas em suas respectivas áreas do conhecimento.

Tabela 2 - Utilização de videoaulas das disciplinas por área do conhecimento.

\begin{tabular}{|c|c|c|c|c|c|}
\hline $\begin{array}{c}\text { Área do } \\
\text { Conhecimento }\end{array}$ & Disciplina & $\begin{array}{c}\text { Média } \\
\text { Ponderada }\end{array}$ & $\begin{array}{c}\text { Área do } \\
\text { Conhecimento } \\
\end{array}$ & Disciplina & $\begin{array}{c}\text { Média } \\
\text { Ponderada }\end{array}$ \\
\hline \multirow{4}{*}{ Ciências Humanas } & História & 2,65 & \multirow{4}{*}{ Linguagens e Códigos } & Literatura & 2,43 \\
\hline & Geografia & 2,14 & & Português & 2,4 \\
\hline & Sociologia & 1,7 & & Redação & 2,52 \\
\hline & Filosofia & 1,74 & & Lingua Estrangeira & 1,85 \\
\hline \multirow{3}{*}{ Ciência da Natureza } & Biologia & 3,34 & Matemática & Matemática & 3,38 \\
\hline & Física & 3,27 & & & \\
\hline & Quimica & 3,42 & & & \\
\hline
\end{tabular}

Entre todas as disciplinas, a da Química é que possui maior valor, 3,42 (mas será mais bem discutido no item seguinte). Analisando por área do conhecimento fica evidenciado que as áreas da Matemática e Ciências da Natureza apresentam os valores mais altos, onde todas as disciplinas tiveram média ponderada superior a 3. Esse cenário é diferente para as áreas de conhecimento Ciências Humanas e Linguagens e Códigos, uma vez que todas as disciplinas tiveram média ponderada menor que 3. Este fato pode apresentar relação com a natureza dos cursos dos alunos, isto é, forte aproximação com conhecimentos ligados à ciências da natureza e matemática.

\section{- Utilizei videoaulas de Química}

Dos 114 respondentes validados, 16 afirmaram nunca terem utilizado videoaula de Química enquanto os outros 98 alunos assistiram com alguma frequência. Em termos percentuaistem-se 14,04 para "Nunca"; 13,16 para "Raramente"; 20,18 para "Ocasionalmente"; 21,93 para "Frequentemente" e 30,70 para "Muito Frequentemente".

Ficou evidenciado que a maioria dos alunos entrevistados utilizou com alta frequência as videoaulas de Química em seus estudos. O índice ficou em 52,63\% para as respostas "Frequentemente" e "Muito Frequentemente". Há de se considerar também que a disciplina de Química obteve a maior média ponderada $(3,42)$ entre todas as disciplinas em relação a utilização de videoaulas. Tal dado pode evidenciar que o uso desse recurso audiovisual ocorre como ferramenta por parte dos alunos para melhor compreender uma disciplina, que embora tenha relação direta com fatos do cotidiano, apresente em seus aspectos conceituais alto nível de abstração. 
Como mencionado anteriormente, apenas 16 alunos, isto é, 14,04\% do total, declararam não terem usado videoaulas de Química como método/recurso de estudo. Constatou-se que entre todos os motivos listados para o não uso de videoaulas de Química, o de "Preferência por outros métodos de estudo" foi o que obteve a maior indicação, atingindo uma média ponderada de 4,41. Os respondentes marcaram a opção "Concordo" 70,59\% neste item. Ao analisar exclusivamente o questionário destes alunos e o relacionar com a questão 1 (Utilizei os seguintes métodos/recursos de estudo), chegou-se aos seguintes valores de médias ponderadas: Sala de Aula - Escola: 4,80; Sala de Aula - Cursinho: 3,27; Livros: 3,64; Apostilas: 3,45; Videoaulas: 1,82.

Percebe-se também, voltando a análise especificamente para a tabela 5, que fatores relacionados ao autogerenciamento dos alunos não foram apresentados entre os principais motivos para a não utilização das videoaulas de Química. Esse fato pode ser evidenciado pelos baixos valores da média ponderada para os motivos "Não possuo disciplina suficiente para uma rotina de estudos" $(1,65)$, "Não possuo autonomia suficiente para organização dos estudos" $(1,24)$, "Possibilidade de distrações em geral (exceto com a internet)" (1,53), "Possibilidade de distrações com a internet" $(2,18)$.

Em relação as respostas no item "Outros", surgiram quatro afirmações. Estas podem apresentar consonância com os aspectos didáticos ("As explicações podem não ser seguras"; "Ótimo professor de química, não precisei de videoaula"; "Nunca senti a necessidade de ver uma videoaula") e de autogerenciamento ("Perde tempo até achar uma videoaula boa, e com isso talvez daria para entender a dúvida").

\section{- Os meus estudos com o uso de videoaulas de Química foram realizados}

Em um busca na literatura se irá encontrar muito mais materiais que falam sobre o uso de videoaulas de Química na sala de aula, abordando aspectos como os usos de linguagens, a exploração de sentidos e o caráter dinâmico (SILVA; LEITE e LEITE, 2016), reforço da explicação prévia do professor, ou ainda como meio de avaliação (FIDELIS e GIBIN, 2016), entre outros, do que fora da sala de aula. Contudo, quando o foco é a preparação para o ingresso no ensino superior, constatou-se que o local onde mais ocorrem os estudos é fora do ambiente escolar.

Dos 98 alunos que utilizaram videoaulas de Química com alguma frequência, a estratificação em relação ao local é a seguinte: na sala de aula a freqüência "Nunca" foi indicada $71,13 \%$ das vezes entre os respondentes. Assim, chegou-se a uma média ponderada de 1,41. Por outro lado, ao analisar o local sendo fora da sala de aula, o valor para a frequência "Muito Frequentemente" foi de 55,67\%, que somado a "Frequentemente" (20,62\%), resulta em 76,29\%. Dessa forma, a média ponderada para esse item foi de 4,26.

Em relação ao uso de videoaulas na sala de aula, uma das barreiras para a integração das TICs na Educação, especialmente com o olhar direcionado para as escolas públicas brasileiras, está relacionada à falta de estrutura adequada, tanto infraestrutura física quanto pessoal (ROSA e EICHLER, 2017). No entanto, há de se destacar que o presente trabalho não evidenciou propositadamente elementos a fim de identificar as causas para o uso ou não de videoaulas na sala de aula, devido ao foco estar na análise do processo de estudo autogerenciado, ou seja, fora da sala de aula.

\section{- Videoaulas de Química como método de estudo Principal ou Complementar}

Provavelmente os 98 alunos que manifestaram a utilização de videoaulas de Química corroboram com o explanado por Moran (2009) sobre a importância de atividades a distância para a aprendizagem. Nesta vertente, 25,53\% dos entrevistados 
manifestaram terem usado como método principal de estudo as videoaulas de Química contra $74,47 \%$, método complementar.

- Entre os motivos que me levaram à escolha do uso de videoaulas de Química (fora da sala de aula) estão

Os itens desta questão tiveram, em uma análise geral, médias ponderadas elevadas, como mostrado na Tabela 3. Observa-se que o valor mais baixo indicado é 3,84, que se refere a "Auto-gerenciamento do tempo" e "Vídeos de curta duração"

Tabela 3 - Motivos do uso de videoaulas de Química (fora da sala de aula)

\begin{tabular}{lc}
\hline \multicolumn{1}{c}{ Motivo } & Média Ponderada \\
\hline Auto-gerenciamento do tempo & 3,84 \\
Auto-gerenciamento dos conteúdos & 4,29 \\
Possibilidade de pausa e repetição do vídeo & 4,68 \\
Qualidade satisfatória do material & 4,06 \\
Linguagem fácil e direta & 4,33 \\
Videos de curta duração & 3,84 \\
Didática com que o conteúdo é transmitido & 4,27 \\
Mobilidade, ou seja, assistir em qualquer lugar & 4,12 \\
Disponibilidade a qualquer momento & 4,60 \\
Otimização do tempo & 4,25 \\
Gratuidade & 4,39 \\
Baixo Custo & 4,04 \\
\hline
\end{tabular}

No outro extremo, isto é, para os maiores índices da média ponderada, têm-se os itens "Possibilidade de pausa e repetição do vídeo" e "Disponibilidade a qualquer momento" com 4,68 e 4,60, respectivamente. Percebe-se assim a importância dada pelos alunos para o aspecto que diz respeito ao gerenciamento das videoaulas, seja para assistirem no momento que julgarem mais oportuno ou avançar nos conteúdos conforme apresentam maior entendimento sobre o mesmo. Lima-Junior et. al. (2017) relatam que, em sua pesquisa sobre o método sala de aula invertida para a disciplina de Química com alunos do ensino médio, a maioria destes afirmaram realizar anotações e perguntas enquanto estudavam usando videoaulas. Para isso, "pausavam e voltavam os vídeos em determinados momentos para um melhor entendimento" (LIMA-JUNIOR et. al., 2017).

Os itens "Gratuidade" e "Baixo Custo", que possuem relação com o aspecto financeiro, aparecem com as médias ponderadas 4,39 e 4,04, respectivamente. Logo, é possível verificar que esse aspecto apresenta-se como um motivo de relevante importância quando do uso de videoaulas de Química.

\section{- Sobre as Plataformas que possuem videoaulas de Química, eu usei:}

A plataforma indicada como a mais utilizada foi o YouTube, tal dado pode ser constatado na Figura 3.

Percebe-se que as plataformas Me Salva e YouTube foram as únicas onde a indicação "Muito Frequentemente" foi superior em relação aos demais níveis de frequência, atingindo $35,8 \%$ e $56,8 \%$, respectivamente. Têm-se no outro extremo, por exemplo, o Kuadro, onde a quantidade de "Nunca" foi muito elevada, 77,9\%.

Ainda sobre o alto índice de "Nunca" é interessante discutir sobre as plataformas Geekie (65,3\%), Hora do Enem (52,6\%) e Khan Academy (61,1\%), uma vez que essas apresentam um suporte mais institucional do que comercial, uma vez que são gratuitas (válido para a Geekie quando inserida como recurso de estudo dentro do Hora do Enem). Como evidenciado no item anterior, os alunos consideram o aspecto financeiro 
um fator importante, no entanto, para essas plataformas supramencionadas, não é possível fazer relação desse fato.

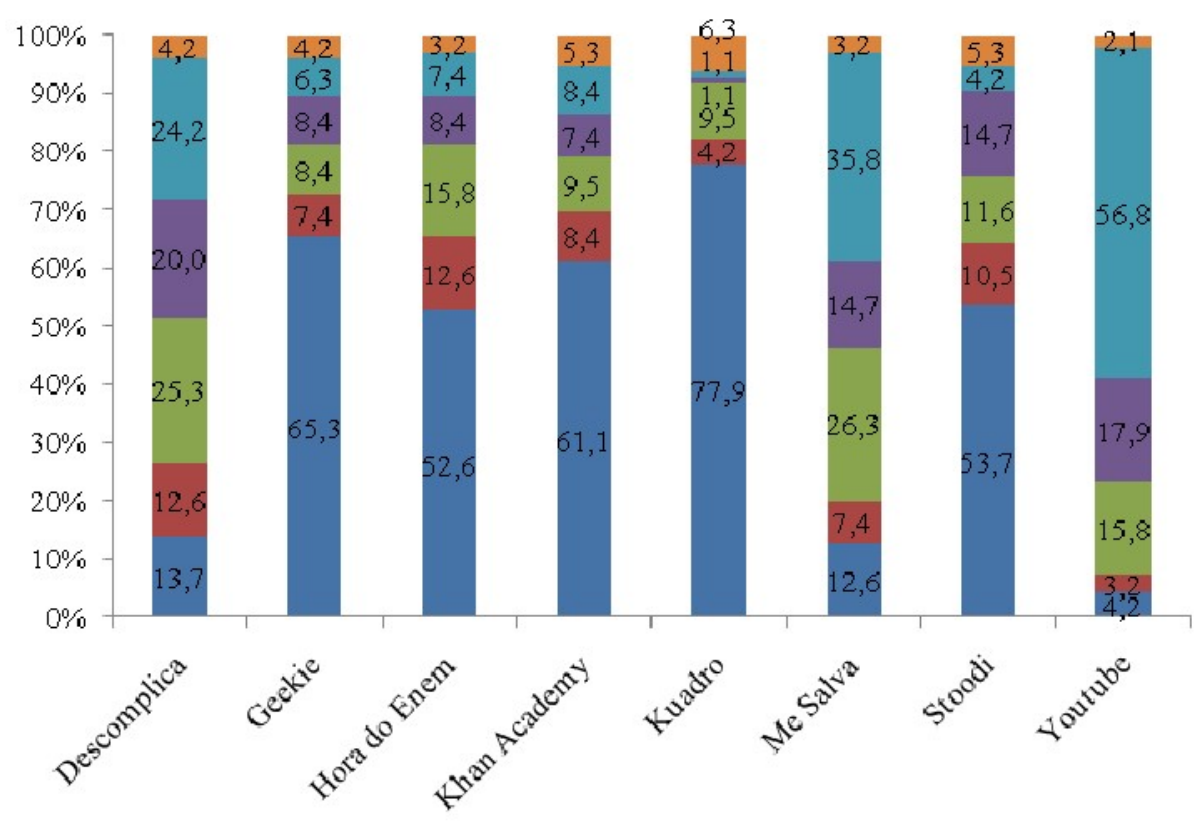

Plataformas de Aprendiz agem Online

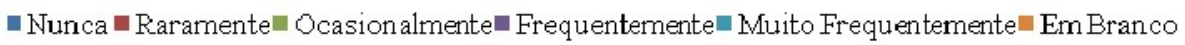

Figura 3 - Utilização das plataformas de aprendizagem online

Por outro lado, o YouTube, uma plataforma gratuita, mostrou-se o ambiente de aprendizagem mais utilizado com uma média ponderada de 4,23 , onde apenas $4,2 \%$ dos alunos afirmaram "Nunca" terem usado para assistirem videoaulas de Química. Corroborando essa informação, Silva e Pereira (2016) constataram que cerca de $70 \%$ dos estudantes pesquisados tem a prática de assistir a vídeos do YouTube para estudar fora de sala de aula, com o propósito, no caso, que inclui o reforço para a escola.

\section{- Os motivos que levaram à escolha da Plataforma}

Observa-se que para esse critério, o valor mais alto foi para "Fácil navegação" $(4,63)$ - maior inclusive que a própria "Qualidade satisfatória dos materiais (videoaulas, exercícios, conteúdos, etc.)" $(4,25)$. Assim, evidencia-se que a necessidade de uma interface de navegação "amistosa" é um item que requer especial atenção dentro de uma plataforma de aprendizagem online. No entanto, não foi possível evidenciar, ou seja, não foi possível relacionar as variáveis, se as plataformas indicadas pelos alunos possuem o sistema e-learning adaptativo, o que, teoricamente, poderia gerar essa maior facilidade de navegação. Com essa tecnologia "cada usuário tem a percepção que o sistema foi projetado especialmente para ele" (GASPARINI et. al., 2011).

$\mathrm{O}$ item "Personalização do ensino (envio de conteúdos e exercícios específicos)", o qual possui convergência com o aspecto avanços tecnológicos, especialmente o conceito de ensino adaptativo, obteve uma média ponderada de 3,25. Tal valor não se encontra nem entre os mais altos, tão pouco os mais baixos. Silva et. al. (2012) preconizam que as videoaulas "por si só, não garantem uma aprendizagem significativa, sendo indispensável a presença do professor como interlocutor nos processos de ensino e de aprendizagem". Percebe-se que esse discurso está mais voltado para a educação dentro do espaço escolar e que vai de encontro com o proposto por 
Muller (2014) ao referenciar um super computador universal como tutor do ensino. Nessa última perspectiva, o ato de estudar estaria totalmente contemplado na abordagem do ensino adaptativo.

Os valores da média ponderada mais baixo ficaram para as "Técnicas de "gamificação" (por exemplo, pontuação, ranking, prêmios, missões, desafios, etc.)" $(1,96)$ e itens que tangenciam o aspecto de interação virtual social ("Grupos de Estudos online" (2,11); "Chat" (2,16);"Fóruns de Discussão" (2,21); e, "Monitorias préagendadas" (2,38)). Sobre este aspecto, Barros e Carvalho (2011) afirmam que a interação virtual promove novas relações que, sob a ótica do aluno, estão diretamente ligadas ao conhecimento, outros alunos e professores. Assim, "a possibilidade de interagir, através das ferramentas tecnológicas, implica rever todos os papéis dos envolvidos no processo ensino e aprendizagem e como também a metodologia utilizada para a promoção dessa aprendizagem" (BARROS e CARVALHO, 2011).

\section{CONSIDERAÇÕES FINAIS}

Foi possível constatar também que a utilização de videoaulas de Química dos alunos entrevistados desta monografia ocorreu com alto grau de frequência, o que talvez possa vir a reforçar aquilo já ratificado por diversos pesquisadores da área de educação de Química: trata-se de uma ciência abstrata a qual necessita recorrer à utilização de diversos modelos e recursos explicativos, tornando-se assim de mais fácil compreensão.

Não se defende com esse trabalho que o uso de videoaulas, especialmente inseridas em ambientes virtuais de aprendizagem contemplados com plataformas de ensino adaptativo, substitua o papel do professor. Defende-se sim, que o uso desse recurso seja (assim como há uma percepção que cada vez mais será) uma ferramenta que, dada suas características e as do meio onde está inserida, ou seja, um universo de crescente tecnológica, sirva como fonte de estudo apropriada. No caso específico de ter como objetivo desse estudo o ingresso no ensino superior, não importa se tais ferramentas serão o método principal ou complementar, uma vez que ficou evidenciado que possuem como características o fomento nos estudantes tanto das habilidades cognitivas quanto a capacidade de auto-gerenciamento de suas atividades.

\section{REFERÊNCIAS BIBLIOGRÁFICAS}

BARROS, M. G.; CARVALHO, A. B. G. As concepções de interatividade nos ambientes virtuais de aprendizagem. Campina Grande: EDUEPB, 2011.

CANDEIAS, C. N. B; CARVALHO, L. H. P. O uso de videoaulas como ferramenta no processo de ensino e aprendizagem em química. In: VII Simpósio Internacional de Educação e Comunicação - SIMEDUC. Aracajú. 2016. p. 1-14.

CASTRO, N. S. E. de. Investigação sobre as formas de preparação para o ingresso no ensino superior: uma educação na sombra ou uma sombra na educação?. Dissertação (Mestrado em Educação), PUCRS. Porto Alegre, 2013.

CONTRERAS, P. E. O.; ELLENSOHN, R. M.; BARIN, C.S. Produção de vídeos na perspectiva da aprendizagem multimídia. RENOTE - Revista Novas Tecnologias na Educação, v. 15, nº 2, p. 1-10, dez, 2017.

CRESWELL, J. W. Projeto de pesquisa: métodos qualitativo, quantitativo e misto. 2a ed. - Porto Alegre: Artmed, 2007. 248 p.

FIDELIS, J. P. S.; GIBIS, G. B. Contextualização como estratégia didática em vídeoaulas de Química. Revista Virtual de Química, v. 8, n. 3, p. 716-722, mai./jun. 2016. 
FORTUNA, R.; FREITAS, P.; MENDES, D.; GOMES, J. C. As propostas de vídeos didáticos apresentadas nos ENPEC de 2009 a 2015. In: XI Encontro Nacional de Pesquisa em Educação em Ciências (ENPEC), Universidade Federal de Santa Catarina, Florianópolis, 2017. p. 1-9.

GASPARINI, I.; KEMCZINSKI, A.; PIMENTA, M. S.; PALAZZO, J. M. O. Modelo do usuário sensível ao contexto cultural em um sistema e-learning adaptativo. Informática na Educação: teoria \& prática, Porto Alegre, v. 14, n. 1, p. 123-135, jan./jun. 2011.

LIMA-JUNIOR, C. G.; CAVALCANTE, A. M. A.; OLIVEIRA, N. L.; SANTOS, G. F.; MONTEIRO-JÚNIOR, J. M. A sala de aula invertida no ensino de química: planejamento, aplicação e avaliação no ensino médio. Revista Debates em Ensino de Química, v. 3, n. 2, p. 119-145, 2017.

LOCATELLI, A.; ZOCH, A. N.; TRENTIN, M. A. S. TICs no Ensino de Química: Um Recorte do "Estado da Arte". Revista Tecnologias na Educação. Ano 7, n. 12, jul. 2015.

MARTINS, P. P.; PIONTKEWICZ, C. M. A efetividade de um sistema de e-learning num contexto do mundo pós-moderno. Revista Travessias, v. 7,nº 2, $18^{\mathrm{a}}$ edição, 2013.

MEDINA, M. N.; BRAGA, M.; REGO, S. C. R. Ensinar ciências para alunos do século xxi: o uso de vídeo-aulas de ciências da natureza por alunos do ensino médio de uma escola pública federal. In: $\mathbf{X}$ Encontro Nacional de Pesquisa em Educação em Ciências (ENPEC). Águas de Lindóia, SP, nov. 2015.

MELO, R. S.; BOLL, C. I. Cultura Digital e Educação: desafios contemporâneos para a aprendizagem escolar em tempos de dispositivos móveis. RENOTE - Revista Novas Tecnologias na Educação, v. 12, nº 1, p. 1-11, jul, 2014.

MORAN, J. M. Aperfeiçoando os modelos de EAD existentes na formação de professores. Educação, Porto Alegre, v. 32, nº 3, p. 286-290, set./dez. 2009.

MULLER, D. A. This will revolutionize education. 2014. (7min23s). Disponivel em: $<$ https://www.youtube.com/watch? $v=$ GEmuEWjHr5c $>$.Acesso em: 26 mar. 2018.

ROSA, M. P. A.; EICHLER, M. L. Tecnologias e professores de Química: um programa brasileiro de desenvolvimento profissional. Revista Internacional de Formação de Professores (RIFP), Itapetininga, v. 2, n.4, p. 113-125, 2017.

SILVA, J. L. et al. A Utilização de Vídeos Didáticos nas Aulas de Química do Ensino Médio para Abordagem Histórica e Contextualizada do Tema Vidros. Química Nova na Escola, São Paulo, v. 34, n. 4, p.189-200. Nov, 2012.

SILVA, M. J.; PEREIRA, M. V. O uso de vídeos por estudantes de ensino médio no estudo das ciências da natureza. V SINECT - Simpósio Nacional de Ensino de Ciência e Tecnologia. 2016.

SILVA, M. S. C. D.; LEITE, Q. S. S.; LEITE, B. S. O vídeo como ferramenta para o aprendizado de química: um estudo de caso no sertão pernambucano. Revista Tecnologias na Educação. Ano 8, v.1, n.1, dez 2016.

SOUZA FILHO, M. P.; SOUZA, A. E. S., GIBIN, G. B. Uso de recursos tecnológicos no ensino de ciências: produção de videoaulas didáticos-experimentais pelos futuros professores. Revista Eletrônica do Programa de Pós-Graduação em Educação e do Departamento de Educação da Faculdade de Ciências e Tecnologia, Unesp, Presidente Prudente, v. 28, n. 3, p. 133-149, set./dez. 2017. 